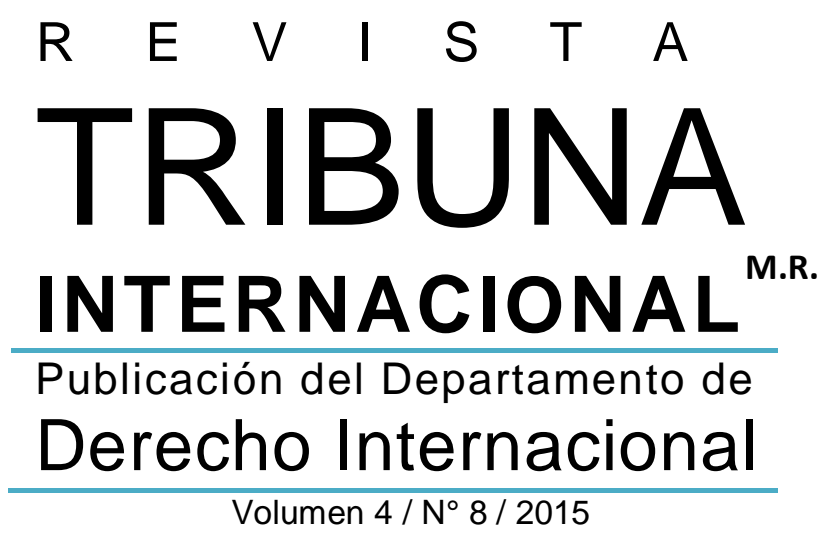

FACULTAD DE DERECHO 


\section{Rector de la Universidad de Chile}

Ennio Vivaldi Véjar

Av. Alameda Libertador Bernardo O'Higgins

1058, Santiago

\section{Representante legal}

Davor Harasic Yaksic

Decano de la Facultad de Derecho

Universidad de Chile

\section{Director Departamento Derecho}

Internacional

Edmundo Vargas Carreño

\section{Director (S) Revista Tribuna Internacional}

Mario Arnello Romo

\section{Editor General Revista Tribuna Internacional}

Luis Valentín Ferrada Walker

\section{Comité Editorial}

Íñigo Álvarez Gálvez (Universidad de Chile, Chile)

Gonzalo Aguilar (Universidad de Talca, Cbile)

José Carlos Fernández Rosas (Universidad

Complutense de Madrid, España)

Claudio Grossman (American University, EE.UU.)

Mattias Kumm (New York University, EE.UU.)

Hugo Llanos (Universidad Central, Chile)

Cecilia Medina (Universidad Diego Portales, Chile)

Elina Mereminskaya (Universidad de Chile, Chile)

Mónica Pinto (Universidad de Buenos Aires, Argentina)

\section{Fundador de la Revista Tribuna Internacional}

Mario Ramírez Necochea $†$

\section{Revista Tribuna Internacional M.R.}

Publicación del Departamento de Derecho Internacional de la Facultad de Derecho de la Universidad de Chile. Su objetivo es fomentar la reflexión, el debate, el análisis y la comunicación sobre el derecho internacional en forma pluralista y con rigor científico. Se publica cada semestre en los meses de junio y diciembre mediante convocatoria abierta a la publicación de artículos y monografías inéditos, comentarios de jurisprudencia, recensiones y comentarios de libros, en los campos de derecho internacional público y privado, derecho internacional de los derechos humanos y relaciones internacionales, tanto en castellano como inglés.

La Revista Tribuna Internacional fue creada por Decreto Exento No 8.466 de la Rectoría de la Universidad de Chile, de 22 de marzo del 2011.

Volumen 4/ No 8 / 2015

www.tribunainternacional.uchile.cl ISSN 0719-482X (versión en línea)

Departamento de Derecho Internacional Facultad de Derecho Universidad de Chile Av. Santa María 076, $4^{\circ}$ piso

Providencia, Santiago de Chile

\section{Diseño y producción:}

Facultad de Derecho

Universidad de Chile

Se autoriza la reproducción total o parcial del contenido de la publicación, siempre que se reconozca y cite el/ la/ los/ las autor/a/es/as y la publicación, no se realicen modificaciones a la obra y no se la utilice para fines comerciales. 


\title{
Corte Internacional de Justicia: Una sentencia errónea y ajurídica. Una derrota política previsible
}

\author{
International Justice Court: A wrongful and lawless sentence. A foreseeable political defeat
}

\section{Mario Arnello Romo}

marnello@derecho.uchile.cl

Abogado. Profesor Titular de Derecho Internacional Público en la Facultad de Derecho de la Universidad de Chile.

Resumen: Se controvierten las afirmaciones hechas en la sentencia de la Corte Internacional de Justicia respecto al contexto histórico en que se enmarcaría la petición boliviana. Se demuestra el desconocimiento de ese tribunal respecto a los hechos más relevantes de la vinculación de Bolivia con el mar. Asimismo, el contexto puesto por la Corte no considera la reiterada mala fe de la política exterior boliviana. Tal Estado que no cumplió y aún violó abiertamente los tres tratados sucesivos firmados con Chile en 1866, 1874 y 1884. Parece evidente que en la nueva etapa procesal en que se encuentra actualmente el litigio estos antecedentes deben ser debidamente considerados e incluido en la Contra Memoria.

Palabras clave: Caso Bolivia c. Chile - contexto histórico - Corte Internacional de Justicia

Abstract: The historical aspects of the judgment International Court of Justice are controverted. Its lack of knowledge about Bolivian effective linkage with the sea is demonstrated. Also, the historic context assumed by the Court did not consider that Bolivia acted repeatedly in bad faith. This State did not accomplish and even openly broke three successive treaties signed with Chile in 1866, 1874 and 1884. On the next phase of this case this historic background should be considered and incorporated on the Counter-memorial.

Keywords: Bolivia v. Chile case - Historical context - International Court of Justice 
Analizar la sentencia que desestimó la objeción preliminar interpuesta por Chile a la demanda de Bolivia, y declaró tener competencia para conocer las controversias sometidas, nos trae necesariamente a un tema más político que jurídico. Hay tres razones para ello: Una, que la Corte, “...cuya función es decidir conforme al derecho internacional las controversias que le sean sometidas" (art.38.1 del Estatuto C:I:J), no se atuvo a ella; dos, que elucubra una forma nebulosa para eludir el objeto y fin de aquella demanda, sosteniendo que no es otro que determinar si existe o no una obligación de negociar un acceso soberano al mar, que Chile habría incumplido; sosteniendo que esa materia no está regulada por el Tratado de 1904, ya que "Bolivia no pide que la Corte declare que tiene un derecho de acceso soberano al mar."; y, tras ese supuesto, agrega que la Corte tiene competencia para determinar si existe o no "la obligación de Chile de negociar un acceso soberano al mar de Bolivia", pero no a determinar el resultado de esa negociación; tres, que la propia Corte fija un contexto histórico - político, que, además de ser improcedente, es una burda tergiversación de la verdad y una burla de su función como tribunal de justicia y de derecho.

En efecto, si cabe formular una observación a la defensa chilena, es la extrema convicción de limitar su rol a la presentación jurídico-procesal de la objeción preliminar, sin intuir ni considerar que Bolivia asumía ante la Corte, tal como lo hacía internacionalmente, el papel de víctima del abuso de fuerza armada que había sufrido al ser privada de su litoral marítimo, el que presentaba como parte integrante del territorio y esencial para su desarrollo nacional. Considerar presentar antecedentes históricos fidedignos y develar tales falsedades, no le pareció oportuno ni compatible. El contexto histórico que hace la sentencia, y que no contradijo ninguno de los dieciséis jueces de la Corte, confirma mi juicio, ya advertido antes, de que era un error no haber previsto incluir una información que restableciera la verdad histórica y geográfica esencial.

El contexto histórico y la relación geográfica que fija la sentencia, encierra -en sus escasas líneas- cinco errores, falsedades y omisiones graves, y configura una tergiversación tan burda de la realidad, que debería ser oficialmente representada a la Corte y, de no ser aclarada debidamente, debe dejarse debida constancia de su rechazo.

La sentencia afirma: 1) “Al momento de su independencia, Bolivia poseía un litoral a lo largo del océano Pacífico, de varios centenares de kilómetros". 
Revista Tribuna Internacional

Volumen $4 \cdot \mathrm{N}^{\circ} 8 \cdot 2015 \cdot$ pp. 51-60

ISSN 0719-482X (versión en línea)

Esto es falso, de falsedad absoluta. No poseía nada. Ni siquiera "derechos expectaticios". No había punto alguno en el litoral incorporado a ella, ni ocupado por bolivianos; es decir, no había posesión alguna que fuese real y efectiva; ni siquiera tenía títulos históricos precisos, que pudiera oponer a los actos de posesión de chilenos desde fines del siglo XVI, y a los títulos históricos que confirmaba la Ley $5^{a}$, de la Recopilación de Leyes de las Indias, 1680, que fijaba el límite entre el Virreinato del Perú y el Reino de Chile, en el litoral, en la quebrada y río Loa. Solo fue idea de Bolivar, en carta a Sucre, Presidente de Bolivia (1825), que ese recién nacido Estado debía tener un puerto en el Pacífico y más adelante, buques de guerra para sostenerlo. Sucre, después de intentar -sin éxito-que el Perú cediera Arica, encomendó a un irlandés que buscara un lugar posible en la desconocida costa. Y éste le recomendó la caleta de Cobija. Solo un decreto proclamando el Puerto La Mar, hizo de primera y única piedra de tal puerto. Bolivia seguiría insistiendo ante Perú, hasta 1842, inútilmente, en la cesión de Arica. El único puerto en el Pacífico, utilizado desde el siglo XVI por la Audiencia de Charcas, y desde 1825 por Bolivia independiente, fue Arica. Cobija, incomunicada con el territorio del altiplano, nunca fue un puerto efectivo, soberano, ni integrado, ni poblado y útil para Bolivia.

El puerto de Cobija siempre fue - como precisa Alcides Argüedas en su Historia de Bolivia. La Fundación de la República - "una creación artificial que no se ocultaba a los mismos fundadores, como el propio Sucre, al tiempo de ordenar la apertura de dicho puerto, escribía a Bolívar, el 11 de mayo de 1826, asegurándole que se abrirá 'pero más con bulla que con provecho', pues el puerto estaba totalmente desvinculado del cuerpo vivo de la nación” (p. 325).

Es importante considerar en este sentido que Bolívar había proyectado la unidad del Alto y Bajo Perú mediante una Confederación de los Andes, a la que se agregaría Ecuador, Colombia, Venezuela y Panamá. En Chuquisaca, el 15 de noviembre de 1826, se firmaron un tratado de federación y otro de límites. Por el segundo, Perú transfería a Bolivia todo el litoral situado al sur del río Sama (límite norte de la Provincia de Tacna) con el puerto de Arica incluido; zona que el tratado indicaba entre el paralelo $18^{\circ}$ y hasta los $21^{\circ}$ de latitud inclusive. En compensación, Bolivia entregaba la Provincia de Apolabamba, del Departamento de la Paz, y el pueblo de Copacabana. 
El Congreso del Perú rechazó ambos tratados, siendo el escollo principal la sesión de Arica. El Congreso boliviano no los aceptó porque estimaba como algo fundamental que previamente debía asegurarse la incorporación de Colombia a la federación.

¿No confirma esto que a la fecha de su independencia, un año antes, Bolivia no tenía puerto ni litoral propio alguno en el Océano Pacífico?

La sentencia, omite -e ignora- que sólo después del rechazo peruano de Arica, y frente al hecho de que Chile había ya creado un puerto en Antofagasta y explotaba covaderas de guano en Mejillones -ambos entre los paralelos $23^{\circ}$ y $24^{\circ}$ de latitud sur-, y dictó una ley, en 1842 , fijando que toda actividad al sur del paralelo $23^{\circ}$ debía pagar gravámenes y derechos a Chile, Bolivia -acogiendo una sugerencia peruana-, protestó y reclamó derechos soberanos en el Desierto de Atacama. Derechos inciertos y variados: hasta el paralelo $27^{\circ}$; o hasta el paralelo $26^{\circ}$; o hasta un río Salado, no ubicado en la geografía. Y en su delirio, el Congreso boliviano aprobó una ley autorizando al Presidente a declarar la guerra a Chile.

La sentencia afirma: 2) "E1 18 de Agosto de 1866, Chile y Bolivia firmaron un Tratado de Límites Territoriales, el cual establecía una "línea de demarcación de fronteras entre ambos Estados, que separaba sus territorios en la costa del Pacífico”.

La sentencia omite, a lo menos, cinco hechos esenciales, porque, al seguir la línea de información de Bolivia, los ignora, aún cuando son parte del contexto de ese tratado. 1) Chile venía saliendo de haber ido a la guerra contra España, para defender al Perú, sufriendo la pérdida de muchos barcos mercantes, y el bombardeo de Valparaíso por la escuadra española. 2) Con igual idealismo americanista, en el Tratado de 1866, cedió a Bolivia gratuitamente el territorio comprendido entre los paralelos $23^{\circ}$ y $24^{\circ}$, no solo en el litoral sino desde el mar a la cordillera, y que incluía la bahía de Mejillones y sus ricas covaderas y el puerto de Antofagasta, construido y poblado por chilenos, y un territorio donde chilenos explotaban minas de plata y exploraban ya las calicheras. 3) Por eso el tratado contempló, además, que los ingresos por derechos de explotación que obtuvieran los dos Estados entre los paralelos $23^{\circ}$ y $25^{\circ}$, se repartirían por mitades. 4) Se complementó, con el acuerdo de que el Gobierno de Bolivia recaudara los ingresos, y después diera cuenta al Gobierno chileno. 5) Omitió algo esencial en referencia a este Tratado: en 1872, al derrocar al gobierno de Melgarejo, el nuevo Gobierno de 
Revista Tribuna Internacional

Volumen $4 \cdot \mathrm{N}^{\circ} 8 \cdot 2015 \cdot$ pp. 51-60

ISSN 0719-482X (versión en línea)

Bolivia DeCretó unilateralmente la nulidAd DEL Tratado De 1866. ¿No creen los jueces de la Corte que es un antecedente importante para medir la consistencia de los derechos que alega tener Bolivia, esta pretensión de sostener derechos sobre un territorio, cuando ella misma destruye el instrumento que los reconoce?

La sentencia afirma: 3):“Esta línea fue confirmada como la línea de frontera en el Tratado de Límites entre Bolivia y Chile, firmado el 6 de Agosto de 1874”.

Una vez más, la sentencia omite -y por ello tergiversa el significado real de los hechos- otros antecedentes esenciales. 1) Chile inicia negociaciones con Bolivia para regularizar las situaciones creadas con el incumplimiento del tratado de 1866, y con la nulidad decretada por el Gobierno boliviano. 2) En 1873, en forma paralela, Bolivia celebra con Perú un Pacto secreto Ofensivo y Defensivo contra Chile. 3) Entonces, en 1874, celebra con Chile el tratado referido, que agrega otras precisiones: a) se anula el tratado de 1866; b) Chile condona las cuentas no rendidas y los ingresos percibidos y retenidos indebidamente por Bolivia. c) se fija como condición expresa de este tratado, la obligación de Bolivia de no aumentar impuestos ni contribuciones, ni fijar nuevos gravámenes a las empresas y sociedades chilenas existentes instaladas al norte del paralelo $24^{\circ}$, por un lapso de 25 años. 4) A fines de 1878, al asumir el Gobierno de Bolivia el general Daza, VIOLA DELIBERADAMENTE LA OBLIGACIÓN QUE LE FIJA EL TRATADO: FIJA UN IMPUESTO ESPECIAL A LAS SALITRERAS CHILENAS, Y SE NIEGA A DEJAR SIN EFECTO EL IMPUESTO. 5) Frente a las protestas de Chile, el Gobierno boliviano embarga los bienes de la salitrera chilena, caduca sus concesiones, y ordena rematar sus bienes, en Febrero de 1879. 5) Chile advierte que la violación del tratado pone término a la cesión del territorio condicionado al cumplimiento de aquella obligación, por lo que reivindica su soberanía y recupera su posesión del mismo. 6) El día fijado para el remate, 300 soldados chilenos desembarcan y pacíficamente, sin disparar un tiro, ocupan la ciudad de Antofagasta, con todas las casas luciendo banderas chilenas. El 93\% de sus habitantes eran chilenos. Solo el 1,5\%, funcionarios públicos y sus familias, eran bolivianos; menor número que los europeos, y que otros grupos de americanos y de asiáticos.

La sentencia afirma: 4): “En 1879, Chile declaró la guerra a Perú y Bolivia, conocida como la Guerra del Pacífico". 
Una vez más, con sus omisiones, tergiversa la verdad. Algunos hechos demuestran otra cosa. Chile ocupó Antofagasta el 14 de Febrero, impidiendo el remate de la salitrera chilena, expresión precisa de la violación deliberada del tratado de 1874 por el Gobierno de Bolivia. El Presidente Daza tuvo conocimiento de ese hecho sólo el 20 de febrero, -(clara demostración de que el litoral no estaba integrado ni comunicado con Bolivia-); pero como se iniciaba el Carnaval, esperó once días de fiestas, antes de adoptar medidas: ordena aumentar el Ejército hasta completar 9.000 hombres; lanza inflamadas arengas públicas; ordena expulsar a todos los chilenos residentes en Bolivia y confiscar sus bienes; y se preocupa de exigir al Gobierno del Perú el cumplimiento del Pacto. Con esa seguridad, el $1^{\circ}$ de marzo de 1879, BOLIVIA DECLARA LA GUERRA A CHILE. Y comienza a preparar esas tropas para cruzar la cordillera y llegar... no a enfrentar a los chilenos en Antofagasta, sino a entrar a Tacna, en abril, donde el aliado lo espera.

Chile, en tanto, al conocer la declaración de guerra de Bolivia, solicita al Presidente del Perú que le informe si la declaración de guerra de Bolivia obligará al Perú a apoyarla; y la respuesta es cuidada pero precisa: "Si hay guerra entre Bolivia y Chile, el Perú está obligado a cumplir lo pactado". Ante esa respuesta, el Gobierno de Chile declara, el 5 de abril, que existe un estado de guerra con Bolivia y con Perú. Es decir, ¡36 días después de la estentórea declaración de guerra hecha por Bolivia!

En carta del Presidente de Bolivia, don Mariano Baptista, de 18 de junio de 1893, al contestar negativamente la petición del general Daza para poder regresar a Bolivia, le imputa: "Se cree que usted provocó la guerra con Chile sin conocimiento del poder extranjero y sin preparación del boliviano; desechando a sabiendas los medios de avenimiento que se le imponían". Lo anterior en referencia a las reiteradas peticiones de Chile, durante el transcurso del año 1878, de ir al arbitraje contemplado en el Protocolo anexo al Tratado de 1874, y que el general Daza rechazó.

Debe anotarse que Chile, sin oposición alguna, ocupa todo el litoral hasta el río Loa, el límite histórico con Perú. No existía ocupación boliviana en punto alguno. Es comprensible que los jueces de la Corte, sugestionados por las alegaciones bolivianas, no puedan creer que ese litoral nunca fue parte integrante de Bolivia. Tal vez, las expresiones del Ministro de Relaciones Exteriores de ese país y posterior Presidente de la República (1892-1896), don Mariano 
Revista Tribuna Internacional

Volumen $4 \cdot \mathrm{N}^{\circ} 8 \cdot 2015 \cdot$ pp. 51-60

ISSN 0719-482X (versión en línea)

Baptista, ante la Cámara de Diputados boliviana, para sostener la necesidad de aprobar el Tratado de 1874, pudiesen hacerlos reflexionar. Cito:

"El aliento de la vida civil y política del interior, apenas se deja sentir allí, donde no podemos intervenir ni con los elementales recursos de la vida económica. Allí, con todos nuestros esfuerzos no podemos proveer a sus habitantes ni de carne, ni del pan, ni del agua; agua, carne y pan los envían Chile y el Perú. Cuando por un golpe de fortuna esas costas han estallado en frutos, no hemos tenido ni población, ni espíritu de empresa, ni capitales que arrojar a esos centros metalíferos, donde se han precipitado como un torrente los chilenos en su inmensa mayoría, fuertes, de vida industrial, formados al calor de asociaciones, habituados al impulso unido y común. ¿Cuál es allí la cifra de nuestra población? No me atrevo a decirlo: lo sabéis tanto como yo. ¿Cuál es la cifra de nuestros capitales? No ignoráis en qué proporción juegan. ¿Destacáis fuerzas? Allí se pierden. ¿Queréis hacer policía? No sabéis por dónde ir.”

Bastaría indicar que en 1879 en la población de Antofagasta, 7.250 habitantes, 6.745 eran chilenos, y 145 personas, sólo funcionarios públicos y sus familiares, eran bolivianos.

La sentencia afirma: 5): “Durante el curso de esta guerra, Chile ocupó el territorio costero de Bolivia".

Tampoco es así. En la ocupación de Antofagasta, hasta llegar al río Loa, no hubo actos de guerra. El Ejército de Bolivia no intentó enfrentar a los chilenos en su supuesto territorio litoral. Se fue a Tacna, a juntarse con el Ejército del Perú. Todo el curso de la guerra se realizó en territorio peruano, y Bolivia, después de la derrota de los ejércitos aliados en la batalla de Tacna, 26 de mayo de 1880, se retiró al altiplano, no participó más en la guerra y dejó sólo a Perú.

La sentencia no es tampoco acuciosa, veraz ni imparcial, en las referencias que hace al Pacto de Tregua de 1884, que "puso fin a las hostilidades entre Bolivia y Chile...”. Afirma: "Bajo los términos del Pacto de Tregua, Chile, inter alia, continuaría gobernando la región costera. Como consecuencia de estos hechos, Bolivia perdió el control de su litoral Pacífico". 
En verdad, el hipotético "control de su litoral costero" Bolivia no lo tuvo nunca en forma efectiva. Una vez más, valdría recordar la realidad reconocida en 1874, por el Ministro ya citado, ante la Cámara de Diputados. El control efectivo lo tuvo Chile, desde abril de 1879. Las hostilidades armadas entre Bolivia y Chile habían terminado cuatro años antes. La Guerra del Pacífico como tal, terminó en 1883, con el Tratado de Paz celebrado entre Chile y Perú.

Lo que continuó, no fue un estado de guerra, sino la incapacidad de los gobiernos de Bolivia de asumir la responsabilidad política de sus actos. Destruir la validez del tratado de 1866, y de la cesión gratuita de litoral y territorio hecho por Chile, porque lo había suscrito el gobernante derrocado; la mala fe que evidencia el hecho de negociar con Chile un nuevo tratado que diera solución aquella situación creada en forma ilícita por Bolivia, mientras suscribía en secreto con el Perú, en 1873, un Pacto Ofensivo y Defensivo contra Chile. Entonces, con esa garantía, suscribe el Tratado de 1874, asumiendo la condición y la obligación de, durante 25 años, no aumentar ni crear nuevos gravámenes a las empresas chilenas ya establecidas en el territorio cedido gratuitamente por Chile. Cuatro años más tarde, un nuevo Gobierno de Bolivia, conspirando con otros interesados en eliminar a las empresas salitreras chilenas de Antofagasta, viola deliberadamente el tratado, caduca las concesiones, embarga sus bienes y rechaza tanto las protestas de Chile como las proposiciones reiteradas de recurrir al arbitraje pactado en el Protocolo del Tratado de 1874. Nueva demostración de mala fe.

La sentencia trae a colación el tratado de 1895. Supone, sin duda, que abona la demanda y la pretensión que Bolivia sostiene. Por el contrario, refleja, una vez más, la mala fé con que actúa y lo irracional que suele ser su política. La sentencia dice que ese tratado no se aplicó, pero no señala la causa; cuando ella no fue otra que la decisión de la Cámara de Diputados de Bolivia, que no aprobó, sino que exigió una serie de modificaciones, lo que llevó a los Gobiernos a no ratificarlo. Pero, lo que confirma aquella mala fe, es que en ese mismo tiempo, Bolivia negocia un tratado secreto con Argentina, por el cual le cede todos sus derechos al territorio de la Puna de Atacama, meseta de 4.000 metros de altura que se extiende entre altos cordones cordilleranos y entre los paralelos $22^{\circ} 30^{\prime}$ y $27^{\circ}$ de latitud sur. Es decir, no obstante haber reconocido en los tratados de 1866 y 1874 que el límite sur era el paralelo $24^{\circ}$, desde el mar a la cordillera, allí lo corría hasta el paralelo $27^{\circ}$, y no obstante el reconocimiento preciso de la 
Revista Tribuna Internacional

Volumen $4 \cdot \mathrm{N}^{\circ} 8 \cdot 2015 \cdot$ pp. 51-60

ISSN 0719-482X (versión en línea)

supremacía soberana de Chile que establecía el Pacto de Tregua de 1884. La intención, una vez más, era intentar crear un conflicto que llevara a la guerra entre Chile y Argentina.

Tampoco es ecuánime ni justa la referencia al Tratado de 1904. Dice la sentencia, "que puso fin oficialmente a la Guerra del Pacífico entre Bolivia y Chile”. (¡La última batalla de esa guerra entre ambos había concluido hacía 24 años!)

Dice la sentencia: "En virtud de este Tratado, que entró en vigor el 10 de marzo de 1905, la totalidad del territorio de la costa boliviana pasó a Chile. Y Bolivia adquirió un derecho de tránsito comercial a los puertos de Chile”.

Los términos del Tratado desmienten el menguado beneficio que habría recibido Bolivia, por el reconocimiento que hace en el tratado, "del dominio absoluto y perpetuo de Chile (de) los territorios ocupados por éste en virtud del artículo $2^{\circ}$ del Pacto de Tregua de 4 de Abril de $1884 ”$.

Basta enunciar las obligaciones que Chile asume en el Tratado:

1) Construir un ferrocarril de Arica con el Alto de La Paz, a su costa, y, a los 15 años, "la sección boliviana de ese ferrocarril se traspasará a Bolivia”. (El costo asumido por estas obligaciones a su entrega a Bolivia -1928- alcanzó una suma superior a siete millones de libras esterlinas).

2) Pagar por las obligaciones que Bolivia incurriera por garantías sobre los capitales que se inviertan para construir -dentro del plazo de treinta años- ferrocarriles internos: Uyuni a Potosí; Oruro a La Paz; Oruro por Cochabamba a Santa Cruz; de la Paz a la región del Beni; y de Potosí por Sucre y Lagunillas Santa Cruz. (Pagos de Chile ascendieron a L 595.000.-).

3) Entrega al Gobierno de Bolivia de L 300.000 en dinero efectivo en dos anualidades.

4) Se otorgó "el más amplio y libre derecho comercial", que incluye el "derecho de constituir agencias aduaneras en los puertos”, y además, su carga no paga almacenaje.

En fin, ventajas que es difícil que pueda alcanzar alguno de los 36 Estados sin litoral ni salida soberana al mar que existen en la actualidad. Y MUCHOS DE ELLOS NO SUFREN ENCLAUSTRAMIENTO Y GOZAN DE UN ALTO DESARROLLO CULTURAL, ECONÓMICO Y SOCIAL. 


\section{LA SENTENCIA OBLIGA A LA CORTE, A UNA SENTENCIA IMPOSIBLE.}

La sentencia afirma: “...la Corte concluye que el objeto del diferendo es saber si Chile está obligado a negociar de buena fe un acceso soberano de Bolivia al Océano Pacífico y en caso afirmativo si Chile ha incumplido dicha obligación." Y, antes de eso, ha pretendido cubrir su posición, advirtiendo que si “...la Corte llegue a la conclusión de que existe tal obligación, no le correspondería tampoco predeterminar el resultado de cualquier negociación que pudiese tener lugar como consecuencia de tal obligación”.

¿Qué significado tendría entonces su sentencia afirmativa?

Las suposiciones pueden ser muy diferentes; pero, también, podría decirse que ninguno. Excepto para la campaña político-demagógica del Presidente de Bolivia.

Por qué, cabe preguntar: ¿puede la Corte obligar a Chile a negociar?

La Corte Internacional de Justicia es, como precisa la Carta de las Naciones Unidas (Capítulo XIV), el órgano judicial principal de las Naciones Unidas, y como tal está obligado por las disposiciones de aquella. El artículo 2 establece: "Para la realización de los propósitos consignados en el Artículo 1, la Organización y sus miembros procederán de acuerdo con los siguientes principios:

“7. Ninguna disposición de esta carta autorizará a las Naciones Unidas a intervenir en los asuntos que son esencialmente de la jurisdicción interna de los Estados, ni obligará a los Miembros a someter dichos asuntos a los procedimientos de arreglo conforme a las presente Carta...”.

Como la "Negociación" es uno de los medios o procedimientos de arreglo de controversias, es evidente que un Órgano de Naciones Unidas no puede obligar a un Estado a negociar con otro, y, en forma muy especial, cuando dicha negociación tiene por finalidad la modificación obligada de un Tratado que fijó una frontera, y una cesión forzada de territorio.

Más aún, cuando la historia demuestra en forma nítida, que no es Chile quien ha actuado repetidamente con mala fe. 